\title{
Evaluation of Senegal's prevention of mother to child transmission of HIV (PMTCT) program data for HIV surveillance
}

Ousmane Diouf ${ }^{1,6}$, Astou Gueye-Gaye ${ }^{1,6}$, Moussa Sarr ${ }^{2 *}$ (D, Abdou Salam Mbengue ${ }^{1,6}$, Christopher S. Murrill ${ }^{3}$, Jacob Dee ${ }^{3}$, Papa Ousmane Diaw ${ }^{1,6}$, Ndeye Fatou Ngom-Faye ${ }^{4}$, Pape Amadou Niang Diallo ${ }^{5}$, Carlos Suarez ${ }^{2}$, Massaer Gueye ${ }^{1,6}$, Aminata Mboup ${ }^{1,6}$, Coumba Toure-Kane ${ }^{1}$ and Souleymane Mboup ${ }^{1,6}$

\begin{abstract}
Background: With the expansion of Prevention of Mother to Child Transmission (PMTCT) services in Senegal, there is growing interest in using PMTCT program data in lieu of conducting unlinked anonymous testing (UAT)-based ANC Sentinel Surveillance. For this reason, an evaluation was conducted in 2011-2012 to identify the gaps that need to be addressed while transitioning to using PMTCT program data for surveillance.

Methods: We conducted analyses to assess HIV prevalence rates and agreements between Sentinel Surveillance and PMTCT HIV test results. Also, a data quality assessment of the PMTCT program registers and data was conducted during the Sentinel Surveillance period (December 2011 to March 2012) and 3 months prior. Finally, we also assessed selection bias, which was the percentage difference from the HIV prevalence among all women enrolled in the antenatal clinic and the HIV prevalence among women who accepted PMTCT HIV testing.

Results: The median site HIV prevalence using routine PMTCT HIV testing data was 1.1\% (IQR: 1.0) while the median site prevalence from the UAT HIV Sentinel Surveillance data was at 1.0\% (IQR: 1.6). The Positive per cent agreement (PPA) of the PMTCT HIV test results compared to those of the Sentinel Surveillance was $85.1 \%$ (95\% Cl 77.2-90.7\%), and the percent-negative agreement (PNA) was 99.9\% (95\% Cl 99.8-99.9\%). The overall HIV prevalence according to UAT was the same as that found for women accepting a PMTCT HIV test and those who refused, with percent bias at $0.00 \%$. For several key PMTCT variables, including "HIV test offered" (85.2\%), "HIV test acceptance" (78.0\%), or "HIV test done" (58.8\%), the proportion of records in registers with combined complete and valid data was below the WHO benchmark of $90 \%$.

Conclusions: The PPA of 85.1 was below the WHO benchmarks of $96.6 \%$, while the combined data validity and completeness rates was below the WHO benchmark of $90 \%$ for many key PMTCT variables. These results suggested that Senegal will need to reinforce the quality of onsite HIV testing and improve program data collection practices in preparation for using PMTCT data for surveillance purposes.
\end{abstract}

Keywords: HIV, Senegal, HIV surveillance, Sentinel surveillance, Prevention of mother-to-child transmission, Antenatal clinic

\footnotetext{
* Correspondence: moussasarr@westat.com

${ }^{2}$ Westat, 1600 Research Blvd, WB 258, Rockville, MD 20850, USA

Full list of author information is available at the end of the article
}

(c) The Author(s). 2018 Open Access This article is distributed under the terms of the Creative Commons Attribution 4.0 International License (http://creativecommons.org/licenses/by/4.0/), which permits unrestricted use, distribution, and reproduction in any medium, provided you give appropriate credit to the original author(s) and the source, provide a link to the Creative Commons license, and indicate if changes were made. The Creative Commons Public Domain Dedication waiver (http://creativecommons.org/publicdomain/zero/1.0/) applies to the data made available in this article, unless otherwise stated. 


\section{Background}

Senegal is one of the countries where the HIV epidemic is concentrated, with an HIV prevalence of less than $1 \%$ in the general population [1] but very high (up to 30\%) among certain key populations such as female sex workers (FSWs) and men who have sex with men (MSM) [2].

The HIV prevalence obtained from sentinel surveillance conducted among pregnant women attending antenatal clinics $(0.7 \%)$ is comparable to what is seen in the general population $(<1 \%)[3,4]$.

Senegal started conducting HIV sentinel surveillance among pregnant women attending antenatal clinics (ANC) as early as 1989, based on WHO/UNAIDS recommendation [5]. Initially, ANC sentinel surveillance (SS) in the country was limited to only 4 regions, and this was gradually extended to cover all 14 regions of the country by 2004 .

By the time we conducted this study in 2011-2012, ANC Sentinel Surveillance was conducted in 45 sites, selected from a total of 198 existing ANCs in the country. Women who attended ANC were generally representative of all pregnant women in Senegal due to high (96\%) ANC coverage [3, 4] and uptake (94\%) [4].

The ANC Sentinel Surveillance rounds were conducted every two years using the unlinked anonymous HIV testing (UAT) method. The UAT method is defined by the collection of left-over blood from routine syphilis testing that has been stripped of all personal identifiers and that is irreversibly made anonymous [5-7]. The left-over blood is then used for HIV testing during the sentinel surveillance surveys. And, in these situations, individuals whose blood tests are positive for HIV cannot be contacted or informed of their status [5].

The Division for the Control of AIDS and Sexually Transmitted Diseases/Ministry of Health $(\mathrm{MOH})$ started offering rapid HIV tests at ANC clinics as part of Senegal's national prevention of mother-to-child transmission (PMTCT) program in 2006 [3]. With the expansion of HIV testing in PMTCT program settings in Senegal, all 45 ANC sites engaged in the HIV Sentinel Surveillance program now provide HIV rapid testing to pregnant women attending ANC services.

The current ANC sentinel surveillance based on unlinked anonymous testing (UAT) has been an important data source for monitoring the HIV epidemic, program planning, and response in the country. However, with the expansion of PMTCT services, currently covering $96 \%$ of all pregnant women $[3,4]$, there is growing interest in using PMTCT program data in lieu of continuing UAT-based ANC Sentinel Surveillance [8]. PMTCT programs collect socio-demographic and HIV testing data similar to that collected by ANC, and it has distinct advantages over ANC surveillance data such as: (a) the potential for larger geographic surveillance coverage that can make HIV estimates more representative, and (b) anticipated lower cost of using PMTCT data for surveillance purposes [8]. Additionally, UAT-based ANC HIV surveillance systems raises ethical concerns as pregnant women tested for HIV in the context of surveillance do not receive their surveillance test result; although they are offered routine HIV testing through the PMTCT program.

However, the use of routine data from PMTCT programs to estimate HIV prevalence may be challenged by factors such as: varying quality of individual-level PMTCT program data at the sites, lack or low-quality control (QC)/quality assurance (QA) for PMTCT HIV testing at the sites, or selection bias which may be due to potential associations between acceptance of PMTCT HIV testing and likelihood of being HIV-positive or of known HIV-positive status [8-10].

Therefore, to effectively transition to utilizing programmatic data for surveillance purposes, it is necessary to assess similarity between UAT surveillance and PMTCT program HIV test results, evaluate the quality of routine PMTCT program data and testing, and identify any potential biases that may be introduced by differences in routine testing uptake [8]. We also assessed the quality of routine PMTCT HIV data and testing to determine the challenges that need to be overcome to use programmatic data as the basis for sentinel surveillance among pregnant women attending ANC clinics, in accordance with WHO-guidelines [8,9]. In 2013, the WHO published guidelines to support country assessments of their readiness to transition from ANC sentinel surveillance to PMTCT-based sero-surveillance [8]. This was followed in 2015 by the Guidelines for Conducting HIV Surveillance among Pregnant Women Attending Antenatal Clinics Based on Routine Program Data [9].

\section{Methods}

The methodology for Sentinel Surveillance in Senegal is based on Joint United Nations Programme on HIV/ AIDS (UNAIDS)/World Health Organization (WHO) recommendations for monitoring HIV among pregnant women attending ANC and has been described elsewhere $[5,6]$. Data from HIV sentinel surveillance surveys are not only used to monitor HIV trends among pregnant women but are also applied as a proxy to estimate the HIV prevalence and incidence among adults in the general population using tools developed by the Joint United Nations Programme on HIV/AIDS (UNAIDS) [5, 6]. Over the past two decades, data from such surveys have been key in monitoring the control of the HIV epidemic in many countries [7].

Conducting nationwide general population surveys such as Demographic and Health Surveys (DHSs) require significant financial resources for Low Income 
Countries and are conducted approximately on a 5-year intervals basis, while lower cost than the later surveys such as the sentinel surveillance among pregnant women are recommended by the world health organization (WHO) on a more frequent basis (about every 2 years) $[5,6]$.

\section{Study size and sample size}

The UAT surveillance round was conducted between December 2011 and March 2012 in 45 sites. All 45 ANC Sentinel Surveillance sites provided PMTCT HIV testing services and were included in the current study. Sites were chosen to represent all 14 regions of Senegal, with two urban sites and at least one rural site per region. As recommended by the WHO guidelines, [5, 8] the 45 sites were selected through convenience sampling based on practicality (physical accessibility; sufficient volume of ANC clients to reach sample-size requirements of 300 and 150 women within a 3-months period for urban and rural sites, respectively); and characteristics that the national surveillance program wanted to be represented in surveillance (urban and rural). Overall, the 45 selected sites included 27 urban and 18 rural sites.

Three hundred women were selected in each urban site and 150 in each rural site for UAT HIV testing during the Sentinel Surveillance period. The inclusion criteria were as follow: any woman with a confirmed pregnancy; Aged between 15 and 49 years, attending first prenatal visit, and providing consent for the PMTCT HIV testing. For the needs of PMTCT data quality assessment and based on WHO recommendations [8], clinic records of 45 pregnant women were selected during the UAT Sentinel Surveillance period and 3 months prior from each site.

\section{HIV testing, data collection tools and methods UAT surveillance biological specimen}

The UAT surveillance round was conducted between December 2011 and March 2012, during which women attending ANC clinics for the first time during the current pregnancy were included for the biological survey at participating sites.

All pregnant women were offered the routine antenatal clinic tests which included syphilis testing. Each woman who consented to syphilis testing had 5-ml of blood drawn. After syphilis testing, left-over blood samples from eligible women were transferred into a separate anticoagulant tube, stripped of all personal identifiers and then sent for HIV testing to the HIV reference laboratory, an ISO 15189 accredited medical laboratory in Dakar, Senegal. The algorithm of the Sentinel Surveillance used a combined 4th generation enzyme-linked immunosorbent assay (ELISA) test using either Murex1.2.0, or Enzygnost Integral. Samples found to be positive at the first ELISA were retested with a rapid test (using either Immuno-Comb or Hexagon HIV1/2) that distinguishes between HIV-1, HIV-2 and HIV 1\&2 positive results. Samples with discordant results from the first two tests were confirmed with the Western Blot (WB) test (using either HIV BLOT 2.2 or INO-LIA 1.2 score). All HIV test results were double entered into a database and all data management procedures were conducted at the reference laboratory.

\section{PMTCT HIV testing}

All pregnant women attending ANC were also offered HIV testing and counseling through the PMTCT services: those who accepted were tested and received their results the same day.

For routine PMTCT program testing in ANC clinics, HIV testing was performed using rapid testing, with first Determine (Alere, Inc., Waltham, Massachusetts, USA) or SD Bioline (Standard Diagnostics, Inc. Yongin-si, South Korea) as an initial screening test at the clinic level (Health Post or Health Center). If the result was nonreactive, the woman was considered HIV-negative; but if the result was reactive, confirmation was done with the Bispot (Orgenics, Yavne, Israel) test at the lab level (Health center only). Women with discrepant results were asked to return for repeat testing 30 days later, with re-sampling done at the sites and retesting at the reference laboratory.

\section{UAT surveillance data collection form}

A data collection form was used by trained the reference laboratory staff to collect the information needed for analysis at the site level. On this paper form, a unique identification number (ID number) was assigned to all eligible pregnant women attending the antenatal clinics during the UAT survey period, whether they accepted PMTCT HIV testing or not. This ID number was not related to any personal characteristics of the women. Key variables captured in the form included socio-demographic data (age, marital status, residence, and education), obstetrical information (gravidity and parity) and PMTCT related information (HIV test offered, HIV test acceptance, HIV test done, and HIV test result delivered). All the data collected from the PMTCT registers were routinely collected by the clinics. The filled forms were then taken to the reference laboratory for data entry and cleaning prior to analysis. In addition to PMTCT HIV test results, HIV test results from UAT Sentinel Surveillance were also included in the form prior to data entry.

\section{PMTCT retrospective data quality assessment}

To assess the quality of routine PMTCT data, study staff examined ANC and lab registers. Forty-five records were abstracted from the sentinel surveillance period, and 
another 45 records were abstracted from the 3 months just prior to Sentinel Surveillance period from each of the 45 sentinel surveillance sites. Every 5 th woman was selected from the list of the ANC registers until the required number was met. Key PMTCT program parameters such as the date of consultation, age, gravidity, parity, HIV test offered, testing acceptance, testing performance, test results, and delivery of test results were evaluated for data validity and completeness. A value was considered complete if it was present and legible in the field, and valid if it was within the expected range of values for that field.

\section{Statistical analyses}

Analyses were performed using STATA version 12 . The overall and site-specific HIV prevalence rates were estimated as a proportion with $95 \%$ confidence intervals. The $95 \%$ confidence intervals (CI) were derived from approximation based on normal distribution. All confidence interval calculations aggregating across sites were based on pooled data and did not account for site level clustering.

To be consistent with WHO recommendations, [8] the median of the site-level HIV prevalence rates and related interquartile ranges (IQR) were also reported.

Positive percent agreement (PPA) and negative percent agreement (NPA) were calculated to assess the level of agreement between the UAT surveillance and routine PMTCT test results. A PPA or a NPA below the benchmarks signified that disagreement of the two testing results exceeded what would have been expected due to statistical variability or the performance characteristics of the two testing algorithms, and was likely to be due to human error in operating ANC HSS or PMTCT HIV tests [5]. For a country such as Senegal with a HIV prevalence close to $1 \%$, and using a 2-test Serial algorithm for HIV diagnosis, the benchmarks recommended by the WHO were 96.6 for the PPA of and 99.9 for the NPA [8].

The prevalence ratio between refusers and non-refusers of PMTCT testing and the percent bias due to refusals that would be introduced if ANC surveillance were based on routine PMTCT tests instead of UAT test results were also calculated. Bias was measured by the parameter "selection bias", defined as the per cent relative change (positive or negative) from the total HIV prevalence.

(among pregnant women who did and did not receive PMTCT HIV testing) to the observed HIV prevalence (among pregnant women who received PMTCT HIV testing) [8]. A percent bias between -10 and $+10 \%$ at all ANC SS sites was considered sufficiently accurate to use for HIV surveillance purposes [8].

All statistical tests were conducted based on two-tailed alternatives and $p<0.05$ was considered significant.
An Excel spreadsheet provided by the U.S. Centers for Decease Control and Prevention (CDC) was used in calculating the percentage of missing, invalid, valid, and complete data for each parameter in the antenatal registers.

\section{Ethical considerations}

Approval to conduct the study was received from the Senegal Ministry of Health's National Ethics Committee and from the Center for Global Health (CGH), U.S. Centers for Disease Control and Prevention (CDC) Atlanta.

All ANC surveillance procedures in Senegal were based on UNAIDS/WHO guidelines [5, 6].

As recommended in the 2003 UNAIDS/WHO Guidelines for conducting HIV sentinel serosurveys among pregnant women and other groups [5], informed consent was not needed for unlinked anonymous HIV testing (UAT) as the left-over blood from routine syphilis testing were stripped of all personal identifiers that could permit personal identification. The privacy of consenting pregnant women and their data confidentiality were ensured through a permanent delinking process that does not allow HIV test results to be traced back to any personal identifying information [5].

Verbal consent was required prior to HIV testing under the PMTCT national public health program. Verbal consent is obtained overall from all women in-country during routine HIV testing as part of the national PMTCT program, as recommended by Senegal's Ministry of Health.

HIV testing was offered to pregnant women free of charge, and positive cases were enrolled for PMTCT services according to national guidelines.

As a reminder, no PMTCT data or biological specimens were collected from pregnant women solely for the purpose of surveillance.

\section{Results}

ANC Sentinel Surveillance was conducted in 45 antenatal clinics; including 27 urban sites and 18 rural sites. For the comparison of HIV testing results, 2 sites were excluded because one of the sites was non-functional and the samples from the second site were not appropriately collected and could not be analyzed. Overall, 8714 pregnant women who met the eligibility criteria for unlinked anonymous testing across the remaining 43 sites were initially selected. Of these 8714 pregnant women, $44(0.5 \%)$ were excluded from the comparison because they refused to be tested for HIV as part of the PMTCT program, $8(0.1 \%)$ were excluded because PMTCT HIV testing was not realized, and $14(0.2 \%)$ were excluded because UAT testing was not realized or the results remained indeterminate after WB testing (see Fig. 1). Finally, 8658 pregnant women with both UAT Sentinel Surveillance and routine PMTCT HIV testing results available were included in the final analysis. 


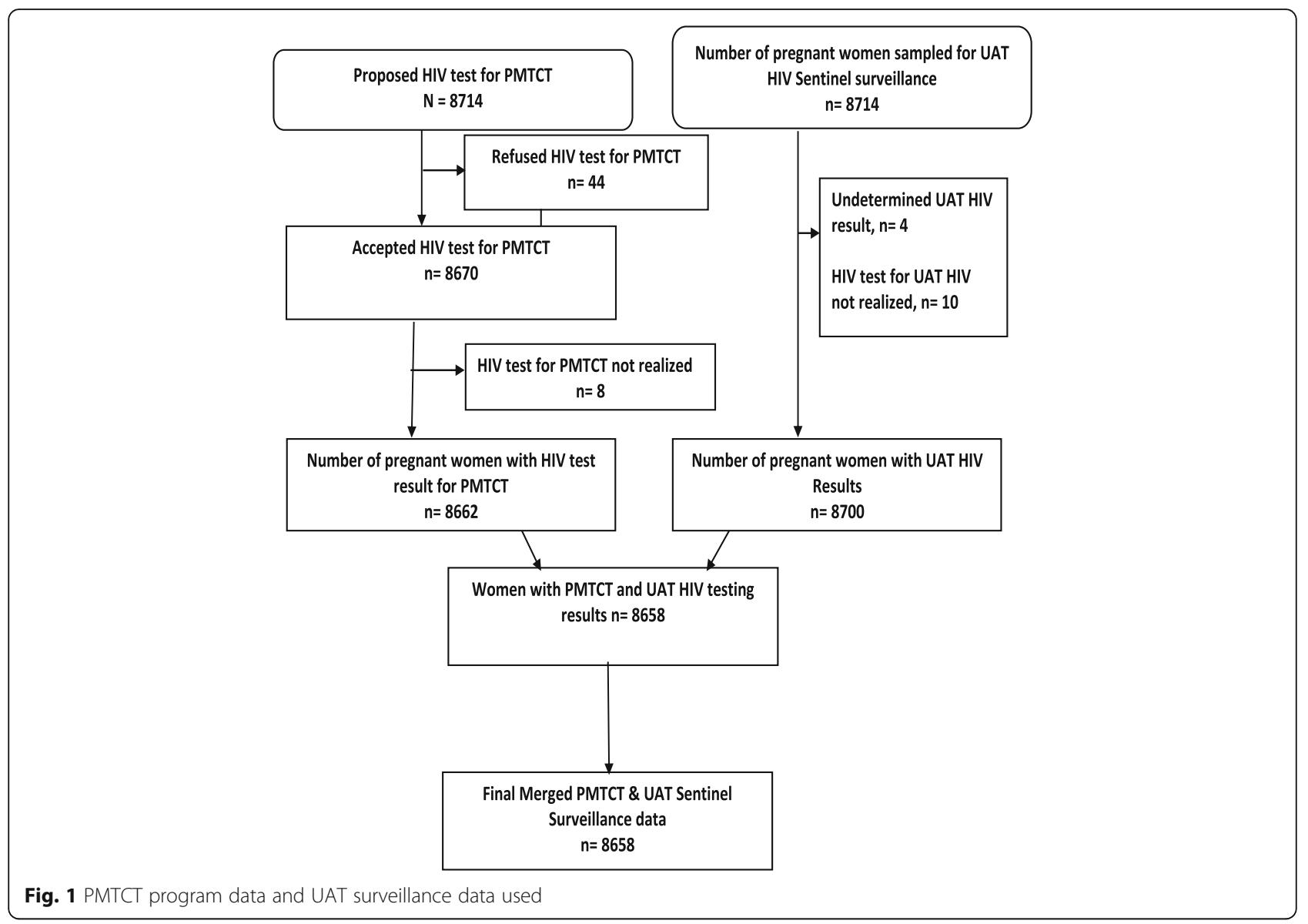

For the women included in the analysis, most of them were in the 15-25 years old age range (51.6\%), followed by the 26-39 years old group (37.4\%), then by the $40+$ years old group $(2.2 \%)$ and finally those who were $<15$ years old $(0.3 \%)$. More than half of the women never went to school (60\%) while close to all of the $(94.3 \%)$ were married. Among those who were married, $24.9 \%$ were from a polygamous relationship. The average number of gravidity was 4.4 and the average number parity was 3.2.

The median site HIV prevalence across the 43 sites based on routine PMTCT testing data was $1.1 \%$ (Inter Quartile Range or IQR: 1.0) while the median site prevalence calculated from the UAT Sentinel Surveillance data was also at $1.0 \%$ (IQR: 1.6) with a non-significant $p$-value. (Table 1 ) The overall HIV prevalence rate was $1.3 \%$ (95\% CI: 1.1-1.6) for women from the PMTCT program data and $1.4 \%$ (95\% CI: $1.2-1.7)$ for those from the UAT Sentinel Surveillance data (data not shown in table). In absolute terms, the overall HIV prevalence was $0.1 \%$ lower when it was measured with the routine PMTCT data versus the Sentinel Surveillance data ( $P$-value non-significant).

The overall PPA of PMTCT and UAT Sentinel Surveillance HIV testing was at $85.1 \%$ (95\% CI: 77.2-90.7), while the overall NPA was 99.9\% (95\% CI: 99.8-99.9) (data not shown in table). The analysis by region showed an overall PPA of $87.1 \%$ (95\% CI: 69.2-95.8) in the West, 81.1\% (95\% CI: 67.6-90.1) in the South, 85.7\% (95\% CI: 42.0-99.2) in the North and 90.0\% (95\% CI: 72.3-97.4) in the central regions of the country.

Our results also showed that the proportion of women who accepted PMTCT HIV testing was 99.4\% (8658/ 8714). Among the 44 women who refused the HIV test for PMTCT, we were able to receive blood samples from 42 of them, and among those, one person was diagnosed positive for HIV at the reference laboratory from UAT. HIV prevalence among those who refused the HIV test for PMTCT was $2.3 \%$ (95\% CI: 0.1-14.1), while among the non-refusers this prevalence was 1.4 (95\% CI: 1.21.7). The overall HIV prevalence among all women, including those who accepted or refused a PMTCT HIV test, was $1.4 \%$ (95\% CI: $1.2-1.6)$, with a low percent bias at $0.00 \%$. (Table 2 ).

The results from the quality assessment of routine PMTCT data are shown in Table 3. For this effort, 1 non-functional site was excluded, and the analysis was done using data from 44 sites. The results showed that variables capturing socio-demographic and obstetrical 
Table 1 Individual-level agreement of PMTCT HIV testing results versus UAT surveillance

\begin{tabular}{|c|c|c|c|c|c|c|c|c|c|c|}
\hline \multirow[t]{2}{*}{ Region } & \multirow[t]{2}{*}{ Site } & \multirow[t]{2}{*}{$\mathrm{N}$} & \multicolumn{4}{|c|}{$\begin{array}{l}\text { Comparison between the results } \\
\text { of HIV testing for PMTCT (R) and } \\
\text { those of Sentinel Surveillance (S) }\end{array}$} & \multirow[t]{2}{*}{$\begin{array}{l}\text { Positive Percent } \\
\text { Agreement }\end{array}$} & \multirow[t]{2}{*}{$\begin{array}{l}\text { Negative percent } \\
\text { agreement }\end{array}$} & \multirow[t]{2}{*}{$\begin{array}{l}\text { PMTCT HIV } \\
\text { Prevalence (\%) }\end{array}$} & \multirow[t]{2}{*}{$\begin{array}{l}\text { UAT } \\
\text { surveillance HIV } \\
\text { Prevalence (\%) }\end{array}$} \\
\hline & & & R-S+ & $\mathrm{R}+\mathrm{S}+$ & $R+S-$ & R-S- & & & & \\
\hline \multirow[t]{9}{*}{ West } & CS Mbao & 174 & 1 & 4 & 0 & 169 & 80.0 & 100.0 & 2.9 & 2.3 \\
\hline & CS Roi Baudoin & 196 & 0 & 2 & 0 & 194 & 100.0 & 100.0 & 1.0 & 1.0 \\
\hline & CS de Mbour & 300 & 2 & 5 & 2 & 291 & 71.4 & 99.3 & 2.3 & 2.3 \\
\hline & CS khombole & 272 & 0 & 2 & 0 & 270 & 100.0 & 100.0 & 0.7 & 0.7 \\
\hline & Centre de santé 10 eme & 238 & 1 & 7 & 1 & 229 & 87.5 & 99.6 & 3.4 & 3.4 \\
\hline & PMI Medina & 300 & 0 & 3 & 0 & 297 & 100.0 & 100.0 & 1.0 & 1.0 \\
\hline & PS Nianing & 138 & 0 & 2 & 0 & 136 & 100.0 & 100.0 & 1.4 & 1.4 \\
\hline & PS Nguekhokh & 175 & 0 & 0 & 0 & 175 & NA & 100.0 & 0,0 & 0,0 \\
\hline & PS de Mboro & 175 & 0 & 2 & 0 & 173 & 100.0 & 100.0 & 1.1 & 1.1 \\
\hline \multirow[t]{8}{*}{ North } & CS Dagana & 166 & 0 & 1 & 1 & 164 & 100.0 & 99.4 & 0.6 & 1.2 \\
\hline & CS Linguere & 99 & 0 & 1 & 0 & 98 & 100.0 & 100.0 & 1.0 & 1.0 \\
\hline & CS Matam & 219 & 1 & 1 & 0 & 217 & 50.0 & 100.0 & 0.9 & 0.5 \\
\hline & CS Louga & 272 & 0 & 0 & 0 & 272 & NA & 100.0 & 0,0 & 0,0 \\
\hline & CS Saint Louis & 112 & 0 & 0 & 0 & 112 & NA & 100.0 & 0,0 & 0,0 \\
\hline & PS Bokidiawé & 150 & 0 & 0 & 0 & 150 & NA & 100.0 & 0,0 & 0,0 \\
\hline & PS Ourossogui & 186 & 0 & 2 & 0 & 184 & 100.0 & 100.0 & 1.1 & 1.1 \\
\hline & PS de Samyabal & 159 & 0 & 1 & 0 & 158 & 100.0 & 100.0 & 0.6 & 0.6 \\
\hline \multirow[t]{12}{*}{ Centre } & CS Diourbel & 297 & 1 & 5 & 0 & 291 & 83.3 & 100.0 & 2.0 & 1.7 \\
\hline & CS Fatick & 164 & 0 & 2 & 0 & 162 & 100.0 & 100.0 & 1.2 & 1.2 \\
\hline & CS Kasnack & 299 & 0 & 3 & 0 & 296 & 100.0 & 100.0 & 1.0 & 1.0 \\
\hline & CS Koungheul & 279 & 0 & 2 & 0 & 277 & 100.0 & 100.0 & 0.7 & 0.7 \\
\hline & CS Ndoffane & 175 & 0 & 3 & 0 & 172 & 100.0 & 100.0 & 1.7 & 1.7 \\
\hline & CS Sokone & 293 & 2 & 2 & 0 & 289 & 50.0 & 100.0 & 1.4 & 0.7 \\
\hline & CS Touba & 298 & 0 & 2 & 0 & 296 & 100.0 & 100.0 & 0.7 & 0.7 \\
\hline & CS kaffrine & 184 & 0 & 3 & 0 & 181 & 100.0 & 100.0 & 1.6 & 1.6 \\
\hline & PS Dianké & 119 & 0 & 0 & 0 & 119 & NA & 100.0 & 0,0 & 0,0 \\
\hline & PS Tataguine & 175 & 0 & 0 & 0 & 175 & NA & 100.0 & 0,0 & 0,0 \\
\hline & PS de Ngoye & 163 & 0 & 2 & 0 & 161 & 100.0 & 100.0 & 1.2 & 1.2 \\
\hline & sOS Kaolack & 300 & 0 & 3 & 0 & 297 & 100.0 & 100.0 & 1.0 & 1.0 \\
\hline \multirow[t]{13}{*}{ South } & C.S Vélingara & 81 & 0 & 1 & 3 & 77 & 100.0 & 96.3 & 1.2 & 4.9 \\
\hline & C.S de Goudomp & 299 & 0 & 4 & 0 & 295 & 100.0 & 100.0 & 1.3 & 1.3 \\
\hline & C.S de Sédhiou & 115 & 0 & 4 & 0 & 111 & 100.0 & 100.0 & 3.5 & 3.5 \\
\hline & CS C Senghor Ziguinchor & 292 & 1 & 11 & 0 & 280 & 91.7 & 100.0 & 4.1 & 3.8 \\
\hline & CS Bignona & 298 & 0 & 9 & 0 & 289 & 100.0 & 100.0 & 3.0 & 3.0 \\
\hline & CS Boumkiling & 159 & 0 & 2 & 0 & 157 & 100.0 & 100.0 & 1.3 & 1.3 \\
\hline & CS Kolda & 298 & 5 & 8 & 0 & 285 & 61.5 & 100.0 & 4.4 & 2.7 \\
\hline & CS Salémata & 71 & 0 & 0 & 0 & 71 & NA & 100.0 & 0,0 & 0,0 \\
\hline & CS Saraya & 33 & 0 & 0 & 0 & 33 & NA & 100.0 & 0,0 & 0,0 \\
\hline & CS Tambacounda & 301 & 0 & 0 & 0 & 301 & NA & 100.0 & 0,0 & 0,0 \\
\hline & PS Missira & 160 & 0 & 0 & 0 & 160 & NA & 100.0 & 0,0 & 0,0 \\
\hline & PS Diawara & 175 & 0 & 0 & 2 & 173 & NA & 98.9 & 1,1 & 0,0 \\
\hline & PS Diaobé & 150 & 4 & 2 & 0 & 144 & 33.3 & 100.0 & 4.0 & 1.3 \\
\hline
\end{tabular}


Table 1 Individual-level agreement of PMTCT HIV testing results versus UAT surveillance (Continued)

\begin{tabular}{|c|c|c|c|c|c|c|c|c|c|c|}
\hline \multirow[t]{2}{*}{ Region } & \multirow[t]{2}{*}{ Site } & \multirow[t]{2}{*}{$\mathrm{N}$} & \multicolumn{4}{|c|}{$\begin{array}{l}\text { Comparison between the results } \\
\text { of HIV testing for PMTCT (R) and } \\
\text { those of Sentinel Surveillance (S) }\end{array}$} & \multirow[t]{2}{*}{$\begin{array}{l}\text { Positive Percent } \\
\text { Agreement }\end{array}$} & \multirow[t]{2}{*}{$\begin{array}{l}\text { Negative percent } \\
\text { agreement }\end{array}$} & \multirow[t]{2}{*}{$\begin{array}{l}\text { PMTCT HIV } \\
\text { Prevalence (\%) }\end{array}$} & \multirow[t]{2}{*}{$\begin{array}{l}\text { UAT } \\
\text { surveillance HIV } \\
\text { Prevalence (\%) }\end{array}$} \\
\hline & & & R-S+ & $\mathrm{R}+\mathrm{S}+$ & $R+S-$ & R-S- & & & & \\
\hline & PS de Kabrousse & 149 & 0 & 2 & 0 & 147 & 100.0 & 100.0 & 1.3 & 1.3 \\
\hline \multirow[t]{2}{*}{ Overall } & & 8658 & 18 & 103 & 9 & 8528 & $\begin{array}{l}85.1 \\
(77.2-90.7 \%),\end{array}$ & $\begin{array}{l}99.9 \\
\text { (95\%Cl: 99.8-99.9) }\end{array}$ & $\begin{array}{l}\text { Median = } 1.1 \\
\text { (IQR: } 1.0)\end{array}$ & $\begin{array}{l}\text { Median = } 1.0 \\
\text { (IQR: 1.6) }\end{array}$ \\
\hline & & & & & & & & & \multicolumn{2}{|c|}{$p$-value $=$ non-significant } \\
\hline
\end{tabular}

1. Percentage of positive agreement $=(R+S+/ R+S+$ and $R-S+)$

2. Percentage of negative agreement $=(\mathrm{R}-\mathrm{S}-) /(\mathrm{R}-\mathrm{S}-$ and $\mathrm{R}+\mathrm{S}-)$

With $\mathrm{R}-/ \mathrm{R}+$ the results of HIV testing for PMTCT

And $\mathrm{S}-/ \mathrm{S}+$ the results of HIV Sentinel Surveillance

a) The positive percentage agreement (PPA) was calculated as the proportion of pregnant women tested HIV-positive through ANC SS HIV testing (using a combined 4th generation ELISA) who were identified as HIV-positive through routine PMTCT testing (using a 2-rapid testing serial algorithm)

b) The negative percentage agreement (NPA) was calculated as the proportion of pregnant women tested HIV-negative through ANC SS HIV testing (using a

combined 4th generation ELISA) who were identified as HIV-negative through routine PMTCT testing (using a 2-rapid testing serial algorithm)

information had very high combined validity and completeness rates. The combined validity and completeness rates were at $98.4 \%$ for age, $99.0 \%$ for gravidity and 98.2\% for parity. However, variables related to PMTCT HIV testing had much lower rates; with combined validity and completeness rates at $85.2 \%$ for HIV test offered, 78.0\% for HIV test acceptance, 58.8\% for test done, and 47.1\% for HIV test results delivered. Citing confidentiality issues, we also noticed a limited recording of HIV test results in the ANC registers, with non-standard ways of keeping HIV test results. For example, some mid-wives kept the list of HIV positive test results with them/in their own purse, and some others chose to make red dots in the register in front of those who were positive.

\section{Discussion}

The HIV prevalence estimate obtained from UAT sentinel surveillance data (1.4\%; 95\% CI 1.2-1.7) was very

Table 2 Effect of missing routine PMTCT HIV data on estimated HIV prevalence rates

\begin{tabular}{|c|c|c|c|}
\hline \multicolumn{4}{|c|}{$\overline{\text { ANC Surveillance HIV Prevalence by Routine PMTCT HIV Test Acceptance }}$} \\
\hline & Total & $\begin{array}{l}\text { Refused PMTCT } \\
\text { HIV testing }\end{array}$ & $\begin{array}{l}\text { Accepted PMTCT } \\
\text { HIV testing }\end{array}$ \\
\hline$\overline{H I V+}$ & 122 & 1 & 121 \\
\hline Total & 8700 & 42 & 8658 \\
\hline HIV Prevalence & $1.4 \%(1.2-1.6)$ & $2.3 \%(0.1-14.1)$ & $1.4 \%(1.2-1.7)$ \\
\hline \multicolumn{4}{|c|}{ Measures of Effect of PMTCT Uptake on HIV Prevalence } \\
\hline Absolute difference ${ }^{a}$ & \multicolumn{3}{|l|}{$+0.9 \%$} \\
\hline Relative difference $^{\mathrm{b}}$ & \multicolumn{3}{|l|}{$+64.3 \%$} \\
\hline Percent bias ${ }^{c}$ & \multicolumn{3}{|l|}{$0.00 \%$} \\
\hline
\end{tabular}

${ }^{a}$ Absolute difference is the HIV prevalence in those whose PMTCT HIV status is missing minus the HIV prevalence in those for whom it is present

${ }^{b}$ Relative difference is the absolute difference divided by the HIV prevalence among those for whom the PMTCT HIV status is present

'Percent bias is the HIV prevalence in those for whom PMTCT HIV status is present minus the overall HIV prevalence, divided by the overall HIV prevalence similar to the estimate obtained from the PMTCT data (1.3\%; 95\% CI 1.1-1.6). However, the overall PPA of 85.1\% was low compared to the general benchmark of 96.6\% recommended by the WHO for a country like Senegal [5]. Assuming that the UAT testing results were accurate, as these were performed at the ISO 15189 accredited national reference laboratory and are considered as the in-country gold standard for HIV testing, the PPA of $85.1 \%$ means approximately 15 out of every 100 HIV positive women received an HIV negative result from the PMTCT program. Our findings of low PPA between PMTCT and UAT HIV testing data are similar to what is seen in most similar studies in Africa, with PPAs of $88.5 \%$ in Mozambique, $75.9 \%$ in Kenya, and 91.2\% in Zimbabwe [11-13].

Regarding the data quality assessment results, the combined data completeness and validity of PMTCT data was high for variables capturing socio-demographic and obstetrical information such as age, gestation or gravidity, but was below the WHO benchmark of $90 \%$ for many variables capturing key PMTCT program information such as HIV testing uptake or the recording of HIV test results. Citing confidentiality issues, we noticed a limited recording in the ANC registers, with non-standard ways of keeping HIV test results. Similar issues were also seen in Kenya by Seguy et al. [14] who described problems with accessing registers, interpreting nurse handwriting and a lack of standardization between practitioners. Incomplete data on HIV testing uptake and lack of key surveillance variables (such as HIV test results) in ANC registers were also seen and described in Kenya and Uganda [14, 15]. On the other hand, some countries such as Botswana have reported high level of completeness of routine data in ANC surveillance sites [16].

The low overall PPA and low to moderate combined data completeness and validity for key PMTCT variables suggested that Senegal still face gaps in the quality of routine PMTCT data systems, HIV testing, and routine 
Table 3 Quality of data in the antenatal registers

\begin{tabular}{|c|c|c|c|c|}
\hline \multirow[t]{2}{*}{ PMTCT program parameters } & \multicolumn{2}{|c|}{ Number $^{\mathrm{a}}$ and Percentage of complete $\&$ valid data } & \multicolumn{2}{|c|}{$\begin{array}{l}\text { Number }{ }^{b} \text { and Percentage of sites with } \\
\text { less than } 90 \% \text { of complete \& valid data }\end{array}$} \\
\hline & $n=3960$ & Mean (\%) & $n=44$ & $\%$ \\
\hline Date of visit & 3948 & 99.7 & 0 & 0.0 \\
\hline Age & 3897 & 98.4 & 1 & 2.3 \\
\hline Number of births & 3920 & 99.0 & 0 & 0.0 \\
\hline Number of live births & 3889 & 98.2 & 2 & 4.5 \\
\hline PMTCT HIV test offered & 3374 & 85.2 & 12 & 27.3 \\
\hline PMTCT HIV test acceptance & 3089 & 78.0 & 24 & 54.5 \\
\hline PMTCT HIV test done & 2328 & 58.8 & 37 & 84.1 \\
\hline PMTCT HIV test results delivered & 1865 & 47.1 & 41 & 93.2 \\
\hline
\end{tabular}

${ }^{a}$ Calculated on 90 pregnant women selected for each site from the register before ( $n=45$ pregnant women) and during ( $n=45$ pregnant women) the Sentinel Surveillance period. Total $=44$ sites participating in DQA $\times 90$ records $=3960$ records

${ }^{\mathrm{b}}$ Number of PMTCT sites participating in DQA

QA for HIV testing [11, 12, 14, 17]. As recommended by the $\mathrm{CDC}$ and the WHO, a quality monitoring and strengthening approach will be needed to allow the use of routine PMTCT data for surveillance while providing the opportunity for Senegal to improve its routine clinical, laboratory and surveillance activities by monitoring and strengthening the quality of routine data, routine HIV testing and routine HIV testing quality assurance [18-20].

The work to improve routine HIV testing and data will be done through a combination of training, mentorship, supervision and continuous quality control (QC)/quality assurance (QA) activities [18, 20, 21]. Developing a robust and high-quality routine HIV testing and data system will only be possible through collaborative work and a joint funding effort, bringing together local and international partners such as the Ministry of Health/the national PMTCT program, the national reference laboratory, the US CDC and/or the Global Fund [21, 22]. Finally, there will be a plan to fully integrate all of this effort into the Ministry of Health's national strategies and plans to guarantee its long-term sustainability [22].

As recommended by the U.S. CDC and the WHO this will be done within a context of a prospective sentinel surveillance design to provide real-time QC/QA to address gaps in routine data and HIV testing and consistently improve HIV data and quality testing standards across all ANC in-country sites [18, 20].

This assessment also found a PMTCT HIV testing uptake of $99.4 \%$ and an overall selection bias in the PMTCT program data of $0.00 \%$. This finding means that non-acceptance of HIV testing among pregnant women in antenatal clinics did not introduce a significant bias in the HIV prevalence estimates based on PMTCT testing. When uptake of PMTCT testing is high, the percent bias is constrained. This finding is similar to what is seen in other countries in Africa with high rates of uptake of PMTCT HIV testing among ANC attendees [11, 13].

\section{Conclusions}

Our results showed no statistically significant difference between overall and median HIV prevalence from routine PMTCT data versus HIV prevalence from traditional ANC Sentinel Surveillance data. However, the low overall PPA and the low combined data completeness and validity for some key PMTCT variables suggest that Senegal should reinforce the quality of onsite HIV rapid testing and program data collection practices as it transitions to using PMTCT data for HIV surveillance needs as recommended by the WHO and the CDC.

A combination of training, mentorship, supervision and continuous quality control (QC)/quality assurance (QA) activities to improve the quality of routine PMTCT data and HIV testing will be required as Senegal transitions to the use of PMTCT program data for surveillance needs. This effort to develop a robust and high-quality HIV testing and routine data system will involve all key national and international partners, and will be integrated into the Ministry of Health's national strategies and plans to guarantee its long-term sustainability.

A prospective sentinel surveillance design is recommended in this setting to provide real-time quality control to address gaps in routine data and HIV testing to allow the use of routine PMTCT data for surveillance while also providing an opportunity for Senegal to improve its routine PMTCT program data and related clinical and laboratory activities in ANC Clinics.

\section{Abbreviations}

AIDS: Acquired Immunodeficiency Syndrome; ANC: Antenatal Clinics; CDC: U.S. Centers for Decease Control and Prevention; CGH: Center for Global Health; ELISA: Enzyme-linked Immunosorbent Assay; FSW: Female Sex Workers; HIV: Human Immunodeficiency Virus; IQR: Interquartile Range; MOH: Ministry of Health; MSM: Men who have Sex with Men; NPA: Negative Percent Agreement; PMTCT: Prevention of Mother to Child Transmission; PPA: Positive Percent Agreement; QA: Quality Assurance; SS: Sentinel Surveillance; UAT: Unlinked Anonymous Testing; WB: Western Blot 


\section{Acknowledgements}

We would like to thank the Division for the Control of AIDS and Sexually Transmitted Diseases/Ministry of Health (MOH) of Senegal, the National Council for the Control of HIV/AIDS, and all participating sites and staff.

\section{Funding}

This work has been supported in part by the President's Emergency Plan for AIDS Relief (PEPFAR) through the U.S. Centers for Disease Control and Prevention (CDC) under the terms of the Cooperative Agreement grant \#5U2GPS002760.

The funders had no role in the design of the study and collection, analysis, and interpretation of data and in writing the manuscript.

The findings and conclusions in this report are those of the author(s) and do not necessarily represent the official position of the funding agencies.

\section{Availability of data and materials}

The datasets used and/or analyzed during the current study are available from the corresponding author on reasonable request.

\section{Authors' contributions}

All authors were responsible for the conception and design of the study. All authors were responsible for acquisition of data and participated in the surveillance activities. OD and ASM performed the data analysis. All authors were all involved in drafting the manuscript or revising it critically for important intellectual content; and all authors read and approved the final version of the manuscript.

\section{Ethics approval and consent to participate}

Approval to conduct the study was received from the Senegal Ministry of Health's National Ethics Committee and from the Center for Global Health (CGH), U.S. Centers for Disease Control and Prevention (CDC) Atlanta. ANC surveillance procedures in Senegal are based on UNAIDS/WHO guidelines. During their first ANC visit, women were asked for verbal informed consent prior to Syphilis testing as part of the national public health program. The left-over blood from routine syphilis testing were then stripped of all personal identifiers and utilized for unlinked anonymous HIV testing (UAT). The privacy of consenting pregnant women and their data confidentiality were ensured through a permanent delinking process that does not allow HIV test results to be traced back to any personal identifying information. Data integrity was assured by a double entry and access was restricted for security measures.

Verbal consent was required prior to HIV testing under the PMTCT national public health program. HIV testing was offered to pregnant women free of charge, and positive cases were enrolled for PMTCT services according to national guidelines.

\section{Consent for publication}

Not applicable.

\section{Competing interests}

The authors declare that they have no competing interests.

\section{Publisher's Note}

Springer Nature remains neutral with regard to jurisdictional claims in published maps and institutional affiliations.

\section{Author details}

'Laboratory of Bacteriology and Virology of Aristide Le Dantec University Hospital, Dakar, Senegal. 'Westat, 1600 Research Blvd, WB 258, Rockville, MD 20850, USA. ${ }^{3}$ Centers for Disease Control and Prevention, 1600 Clifton Road, Atlanta, USA. ${ }^{4}$ Division pour la Lutte Contre Le SIDA et les ISTs (DLSI), Dakar, Senegal. ${ }^{5}$ Conseils National pour la Lutte Contre le SIDA (CNLS), Dakar, Senegal. ${ }^{6}$ Present Address: IRESSEF: Institut de Recherche en Santé, de Surveillance Epidémiologique et de Formations, Arrondissement 4 Rue 2 D1, Pole Urbain de Diamniado, 7325 Dakar, BP, Senegal.
Received: 1 November 2017 Accepted: 5 November 2018

Published online: 20 November 2018

\section{References}

1. Agence Nationale de la Statistique and ICF International (2012). 2010-11 Senegal Demographic and Health and Multiple Indicators Survey: Key Findings. Calverton: ANSD and ICF International; 2012.

2. Conseil National de Lutte contre le SIDA (CNLS). Plan Stratégique de lutte contre Les Infections Sexuellement Transmissibles, le VIH, et le SIDA 2014 2017. République du Sénégal, Primature, Conseil National de Lutte Contre le Sida, 2014. https://www.cnls-senegal.org/wp-content/uploads/2018/06/PSN2014-2017.pdf.

3. Ngom Faye NF. Rapport sur La Prévention de la Transmission Mère-enfant du VIH au Sénégal. République du Sénégal, Ministère de la Santé et Action sociale, Division de la lutte contre le Sida et les Infections Sexuellement Transmissibles; 2014

4. Division de la lutte contre le Sida et les Infections Sexuellement Transmissibles. Synthèse Prévention de la Transmission Mère-Enfant. République du Sénégal, Ministère de la Santé et Action sociale, Division de la lutte contre le Sida et les Infections Sexuellement Transmissibles; 2014

5. World Health Organization/UNAIDS 7.10. UNAIDS/WHO Working Group on Global HIV/AIDS \& STI Surveillance. Guidelines for conducting HIV sentinel serosurveys among pregnant women and other groups. Geneva: WHO/ UNAIDS; 2003.

6. Stover J, Brown T, Puckett R, Peerapatanapokin W. Updates to the Spectrum/estimations and projections package model for estimating trends and current values for key HIV indicators. AIDS. 2017;31(Suppl 1):S5-S11.

7. GBD 2015 HIV Collaborators. Estimates of global, regional, and national incidence, prevalence, and mortality of HIV, 1980-2015: the Global Burden of Disease Study 2015. Lancet HIV. 2016;3(8):e361-87.

8. World Health Organization. Guidelines for Assessing the Utility of Data from Prevention of Mother-to-Child Transmission (PMTCT) programmes for HIV sentinel surveillance among pregnant women. Geneva: World Health Organization; 2013. http://apps.who.int/iris/bitstream/10665/85512/1/ 9789241505611_eng.pdf?ua=1.

9. World Health Organization. Guidelines for conducting HIV surveillance among pregnant women attending antenatal clinics based on routine programme data. Geneva: World Health Organization; 2015. http://www. who.int/hiv/pub/guidelines/si-guidelines-pregnant-women/en/.

10. Marsh KA, Bolu O, Bodika S, Seipone K, Wonkongkathep S, Baryarama F, Yansaneh A, Eure-Miller C, Garcia-Calleja JM. How can PMTCT program data be used for the purposes of HIV surveillance? jHASE. 2010;2:5.

11. Young PW, Mahomed M, Horth RZ, Shiraishi RW, Jani IV. Routine data from prevention of mother-to-child transmission (PMTCT) HIV testing not yet ready for HIV surveillance in Mozambique: a retrospective analysis of matched test results. BMC Infect Dis. 2013:13:96.

12. Sirengo M, Rutherford GW, Otieno-Nyunya B, Kellogg TA, Kimanga D, Muraguri N. Umuro M, Mirjahangir J, Stein E, Ndisha M, Kim AA. Evaluation of Kenya's readiness to transition from sentinel surveillance to routine HIV testing for antenatal clinic-based HIV surveillance. BMC Infect Dis. 2016;16(1):113.

13. Gonese E, Mushavi A, Mungati M, Mhangara M, Dzangare J, Mugurungi O, Dee J, Kilmarx PH, Shambira G, Tshimanga MT, Hargrove J. Zimbabwe ready to transition from anonymous unlinked sero-surveillance to using prevention of mother to child transmission of HIV (PMTCT) program data for HIV surveillance?: results of PMTCT utility study. 2012 BMC Infect Dis. 2016;16(1):97

14. Seguy N, Hladik W, Munyisia E, Bolu O, Marum LH, Diaz T. Can data from programs for the prevention of mother-to-child transmission of HIV be used for HIV surveillance in Kenya? Public Health Rep. 2006; 121(6):695-702.

15. Fabiani M, Yoti Z, Nattabi B, Ayella EO, Opio AA, Musinguzi J, García Calleja JM, Declich S. Adjusting HIV prevalence data from a program for the prevention of mother-to-child transmission for surveillance purposes in Uganda. J Acquir Immune Defic Syndr. 2007;46(3):328-31.

16. Seipone K. Utility of PMTCT program data for HIV surveillance in Botswana Preliminary results. In: 2nd Global HIV/AIDS Surveillance Meeting (Session VIIB). Bangkok; 2009.

17. Hladik W, Masupu K, Roels T, Plipat T, Kaharuza F, Bunnell R, Seguy N, Marum LH. Prevention of mother-to-child transmission and voluntary counseling and testing programme data: what is their utility for HIV surveillance? AIDS. 2005;19(Suppl 2):S19-24. 
18. Parekh BS, Kalou MB, Alemnji G, Ou CY, Gershy-Damet GM, Nkengasong JN. Scaling up HIV rapid testing in developing countries: comprehensive approach for implementing quality assurance. Am J Clin Pathol. 2010;134(4):573-84.

19. Ayana G. Ensuring Accuracy and Reliability of HIV Testing in Ethiopia. African Society of Laboratory Medicine Consultative Meeting: Improving Access and Increasing Quality of HIV Testing in Africa. Dar es Salaam: United Republic of Tanzania; 2014.

20. Division of Global HIV \& Tuberculosis. Clinical Surveillance: Bringing data together to control HIV. US Centers of Disease Control and Prevention, Center For Global Health, Division of Global HIV \& Tuberculosis; 2016. https://www.cdc.gov/globalhivtb/who-we-are/resources/keyareafactsheets/ clinical-surveillance.pdf.

21. Dee J, Garcia Calleja JM, Marsh K, Zaidi I, Murrill C, Swaminathan M. HIV Surveillance Among Pregnant Women Attending Antenatal Clinics: Evolution and Current Direction. JMIR Public Health Surveill. 2017:3(4):e85.

22. Mbengue MAS, Sarr M, Diaw PA, Diallo PAN, Toure MD, Ngom-Faye NF, Gueye B, Toure-Kane NCT, Mboup S. Establishing a national laboratory quality system for HIV diagnosis and monitoring in resource-limited settings: experience from Senegal. Afr J Lab Med. 2016;5(2):51-4.

Ready to submit your research? Choose BMC and benefit from:

- fast, convenient online submission

- thorough peer review by experienced researchers in your field

- rapid publication on acceptance

- support for research data, including large and complex data types

- gold Open Access which fosters wider collaboration and increased citations

- maximum visibility for your research: over $100 \mathrm{M}$ website views per year

At $\mathrm{BMC}$, research is always in progress.

Learn more biomedcentral.com/submissions 